\title{
User Perceived Value and Continued Participation in Barrage Video
}

\author{
Lulu Ye $\mathrm{Ya}^{1, \mathrm{a}}$ \\ ${ }^{I}$ Business School, Jiangxi Normal University, Nanchang, Jiangxi, China \\ ${ }^{a}$ 949607840@qq.com \\ *corresponding author
}

\begin{abstract}
It is a reality that barrage video is getting prevailing for being able to satisfy users' demand of real-time interaction. In the cut throat competition, how to hold a person's attention effortlessly and promote continued participation is still a vital issue. This paper aims to study the relation between user perceived values and continued participation in the context of barrage video. To obtain practical implications, a survey has been implemented. The results reveal that information value has positive impacts on continued participation behavior, and its effect is completely mediated by satisfaction. Entertainment value can also promote the continued participation behavior, in which satisfaction plays a part of mediating role. Social value has no significant direct influence on the continued participation behavior.
\end{abstract}

Keywords: perceived value, continued participation, barrage video

\section{INTRODUCTION}

Online video has become one of the most important forms of online entertainment for users. According to the report on the development of China's Internet audio-visual Research, China's online video users has reached 609 million, accounting for $76 \%$ of the total number of Internet users by June 2018 [1]. With the development of science and technology, users are no longer satisfied with passively receiving information, but long for more communication and interaction. $73.7 \%$ of users like to read comments while watching videos [2]. Thus, a new way of making comments - barrage came into being. At the beginning, barrage users were mainly AGC (animation, game, comic) enthusiasts. However, in the post-modern context of the Internet, the barrage slowly began its process of mainstreaming in its development [3].Traditional online video websites such as Tencent and iQIYI have followed the example of professional barrage video websites like AcFun and Bilibili, adding barrage functionality on their websites. According to the survey, more than $50 \%$ of users are willing to watch the barrage [2].It can be seen that barrage promotes users' willingness to comment in an interactive way which is completely different from the traditional way and is gradually accepted by the public. Barrage video has gone from niche to mass.

Nevertheless, in barrage video, users are not only the recipients of information, but also the creators of content. Therefore, whether it can indeed provide users with interesting and valuable information and promote their continuous participation is still worth studying. Based on perceived values, this paper tries to explore the factors that influence the viewing and usage of barrage and figure out what users pay more attention to in the process of participation, in order to offer some suggestions for the development of barrage video.

\section{LITERATURE REVIEW CONCEPTUAL MODEL}

AND

\subsection{Literature Review}

\subsubsection{Research on Barrage}

Originally, Barrage refers to a large number of comments that occupy the screen and are basically consistent in content at the same time[4]. After being introduced into China, the meaning changed. Even a single comment can be regarded as barrage. That is to say, no matter how many comments, as long as they conform to the characteristics of fluidity and coverage, they are collectively called barrage[5].

\subsubsection{Research on Perceived Value}

Zeithaml proposed that perceived value is the overall evaluation of the utility of a product or service made by consumers based on the perception of costs and returns in the consumption process [6].The most common example of this definition is the consumer's trade-off between price and quality in the retail industry. With the development of the Internet, perceived value is no longer limited to the attributes of products. Thus, Woodruff gave a more comprehensive definition, that is, perceived value is the customers' perception preference and evaluation of certain attributes, performance and use results that help (or hinder) them to achieve their goals in the process of using products[7]. The early dimension division is mainly based on whether the product can realize its function and achieve the expected purpose. For example, PIMS (Profit Impact of Market Strategies) considered that customer value is determined by product quality and relative price[8].With the deepening of 
research, Sheth was no longer limited to product quality and price, but brought up a broader dimension, namely five dimensions of social value, emotional value, functional value, cognitive value and conditional value [9]. Sweeney\& Soutar believed that the concept of perceived value is different from satisfaction, and divided it into emotional value, social value, functional value and functional value [10].

\subsubsection{Research on Customer Satisfaction and Continued Participation}

Customer satisfaction was firstly proposed by Cardozo who defined it as customers' repeat buying[11]. Based on the previous study, Oliver put forward the theory of expectation inconsistency. Expectation means customer's expectation of the product benefits that they'll gain and performance refers to customer's perception of the actual experience of the product or service. The difference between the two is inconsistency. When the inconsistency is greater than zero, the performance is higher than the expectation and the customer is satisfied. Otherwise, they won't be satisfied[12]. According to Oliver's theory, Bhattacherjee analyzed the behavioral characteristics of information system users and found that, unlike the expectation formed by consumers through online comments before purchase, consumers' expectation after initial participation was more convincing. In this process, consumers' satisfaction will affect their intention of continuous use, which will further affect their behavior of continuous use[13].

\subsection{Conceptual Model}

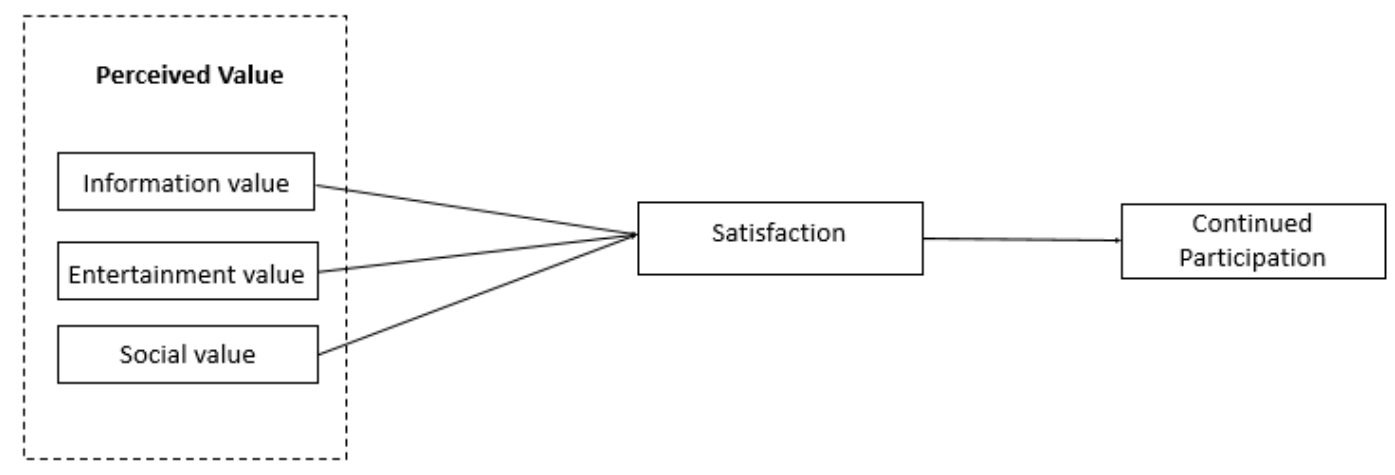

Figure 1 Conceptual Model

According to what mentioned above, this paper proposes the following hypotheses

H1: Satisfaction has a positive impact on continuous participation

Information value refers to the degree of perception of users in barrage video to meet their information needs. In barrage video, barrage can provide users with a lot of information, such as plot review and interpretation in movies and TV dramas, background of video in professional video, professional knowledge and popular science, etc. The immediacy and pertinence of such information is conducive to the satisfaction of users' thirst for knowledge[14]. When the user's thirst for knowledge is satisfied, it is possible to continue using the barrage. The author proposes the following hypotheses:

H2a: Information value will positively affect the continuous participation behavior

H3a: Satisfaction mediates the influence of information value on persistent behavior

Social value refers to the social utility acquired by users in barrage video, such as the recognition of others and the improvement of interpersonal relationship. In barrage video, users gather together due to similar interests to form a natural community and express their ideas for a specific detail or picture in video. For the starters of bullet screen, repeated refresh of their bullet screen is a kind of affirmation from others, which satisfies their own psychological needs and makes them satisfied. At the same time, it also strengthens their sense of identity to the group, and the strong group identity will have a lasting impact on the actions of participants[15]. The author proposes the following hypotheses:

H2b: Social value will positively affect the sustained participation behavior

H3b: Satisfaction plays an intermediary role in the influence of social value on sustainable behavior

Entertainment value refers to the emotions that users get in the barrage video, such as pleasure. In barrage video, some plain contents are likely to become vivid because of their unique humor and insight, which brings a sense of pleasure to users and forms a carnival sensory experience and emotional release[16]. According to the research results of knowledge sharing behavior of Chiu members in the virtual community, the sense of pleasure will promote the continuous sharing intention of members and indirectly affect the continuous participation behavior[17]. The author proposes the following hypotheses:

H2c: Entertainment value will positively affect the sustained participation

H3c: Satisfaction mediates the influence of entertainment value on sustained behavior 
Table 3 Intermediate

\begin{tabular}{cccc}
\hline & Model1 & Model 2 & Model 3 \\
\hline $\begin{array}{c}\text { Information } \\
\text { Value }\end{array}$ & 0.022 & 0.084 & 0.000 \\
$\begin{array}{c}\text { Social Value } \\
\text { Entertainment } \\
\text { Value }\end{array}$ & 0.110 & 0.555 & 0.073 \\
$\begin{array}{c}\text { Satisfaction } \\
\text { R2 }\end{array}$ & 0.000 & 0.003 & 0.007 \\
Adjustedr2 & 0.403 & 0.486 & 0.491 \\
F & 31.591 & 33.118 & 44.763 \\
df & 3 & 4 & 3 \\
\hline
\end{tabular}

Table 1 Reliability

\begin{tabular}{cc}
\hline VARIABLE & Cronbach's $\alpha$ \\
\hline Information Value & 0.783 \\
Entertainment Value & 0.719 \\
Social Value & 0.719 \\
Satisfaction & 0.787 \\
Continued Participation & 0.675 \\
\hline
\end{tabular}

Table 2 Validity

\begin{tabular}{|c|c|c|c|c|}
\hline VARIABLE & ITEM & FIF & $\mathrm{KMO}$ & Bartlett P \\
\hline \multirow{3}{*}{$\begin{array}{l}\text { Information } \\
\text { value }\end{array}$} & IVQ1 & 0.882 & 0.673 & 0.000 \\
\hline & IVQ2 & 0.830 & & \\
\hline & IVQ3 & 0.793 & & \\
\hline \multirow{4}{*}{ Social value } & SVQ1 & 0.662 & 0.613 & 0.000 \\
\hline & SVQ2 & 0.871 & & \\
\hline & SVQ3 & 0.852 & & \\
\hline & EVQ1 & 0.595 & 0.724 & 0.000 \\
\hline \multirow{3}{*}{$\begin{array}{c}\text { Entertainment } \\
\text { value }\end{array}$} & EVQ2 & 0.811 & & \\
\hline & EVQ3 & 0.820 & & \\
\hline & EVQ4 & 0.722 & & \\
\hline \multirow{3}{*}{ Satisfaction } & SAQ1 & 0.852 & 0.703 & 0.000 \\
\hline & SAQ2 & 0.842 & & \\
\hline & SAQ3 & 0.818 & & \\
\hline \multirow{3}{*}{$\begin{array}{c}\text { Continued } \\
\text { Participation }\end{array}$} & CPQ1 & 0.682 & 0.627 & 0.000 \\
\hline & CPQ2 & 0.842 & & \\
\hline & CPQ3 & 0.826 & & \\
\hline
\end{tabular}

The reliability coefficients of all dimensions are greater than 0.6 , indicating that the reliability quality of the research data is good and can be used for further analysis. As can be seen from the above table, KMO values are all greater than 0.6, which means that the data has validity. In addition, the factor loading coefficients are all greater than 0.5 , indicating that there is a corresponding relationship between options and factors. In conclusion, the validity of the questionnaire is acceptable.
Model 1 is the regression model of information value, social value and entertainment value to continuous participation. As can be seen from the above table, the $\mathrm{P}$ value of information value $(0.022)$ and entertainment value $(0.000)$ is less than 0.05 and reaches the significance level, that is, $\mathrm{H} 2 \mathrm{a}$ and $\mathrm{H} 2 \mathrm{c}$ pass the test. However, the social value $(0.110)$ did not reach the significance level, so $\mathrm{H} 2 \mathrm{~b}$ failed the test.

Model 2 is the regression model of information value, social value, entertainment value and satisfaction degree to continuous participation. As can be seen from the table, satisfaction has a significant impact on continuous participation behavior, and $\mathrm{H} 1$ is verified.

Model 3 is the regression model of information value, social value and entertainment value to satisfaction. Refer to Baron's mediation effect test steps [22] : (1) regression of independent variable to dependent variable;(2) when the main effect is significant, the independent variable returns to the mediating variable;(3) regression of independent variable and intermediary variable to dependent variable and observation of regression coefficient. According to this method, the mediating effect test results in this paper are as follows. First, $\mathrm{H} 3 \mathrm{~b}$ has not been verified because social value has no significant influence on the continuous participation behavior and satisfaction has no mediating effect. Secondly, the information value has a significant influence on the continuous participation behavior, and the influence is not significant after adding the satisfaction degree of mediating variable, indicating that satisfaction degree plays a fully mediating role in the influence of information value on the continuous participation behavior, so $\mathrm{H} 3 \mathrm{a}$ is verified. Finally, the entertainment value has a significant influence on the continuous participation behavior (regression coefficient 0.479). When the satisfaction of mediating variable is added, the influence is significant, but the regression coefficient drops to 0.257 .Sobel's test $p$ value is 0.000 , which is significant (as shown in table 4), indicating that satisfaction plays a part of mediating role in the influence of entertainment value on continuous participation behavior, so $\mathrm{H} 3 \mathrm{c}$ is verified.

Table 4 Sobel

\begin{tabular}{cccc}
\hline Effect & Se & $\mathrm{Z}$ & $\mathrm{P}$ \\
0.3087 & 0.0632 & 4.8808 & 0.0000 \\
\hline
\end{tabular}




\section{CONCLUSION}

The rapid development of the Internet enables users to have their say. In order to enhance the participation of users, barrage video needs to satisfy the demands of users. It is found in this paper that information value can positively affect the continuous participation behavior of users, and its role is completely mediated by satisfaction. Entertainment experience can also promote continuous participation, in which satisfaction plays a part of the intermediary role. Social value has no significant direct influence on the behavior of continuous participation. In conclusion, information value and entertainment value are important factors that affect the continuous participation of users. Therefore, it is necessary for video website to strengthen the management of barrage to ensure that users can obtain interesting and useful information. Here are management implications. Firstly, it is an effective way to encourage users to register with real names, which will increase users' sense of responsibility for what they send. Secondly, making efforts in barrage education to avoid ba. Finally, improve the supervision mechanism.

\section{REFERENCES}

[1] Zhou Jie, "Report on the Research and Development of China's Internet audio-visual Research", Chengdu: China Online Audiovisual Program Service Association. 2018.

[2] Cool Penguins, "Online Video Using Survey Report: Barrage Usage Exceeds Subscription Usage", http://www.199it.com/archives/347102.html. 2015.

[3] Gao Xue, "Resistance and Acceptance: Study on the Relationship between Barrage Subculture and Mainstream Culture", Jinan University. 2015.

[4] Lv Peng, Xu Fanjia, "Barrage Pool as a Grocery Store: Barrage Research on Barrage Video", International Press. 2016: 38(10): 28-41.

[5] Ding Yining. "Audience Performance and Imagination: Study on the Population of the Use of Barrage", News \& Spring. 2015(04): 87-95.

[6] Zeithaml V A., "Consumer Perceptions of Price, Quality and Value: A Means-End Model and Synthesis of Evidence", Journal of Marketing. 1988: 52(3): 2-22.

[7] Woodruff R B., "Customer Value: The Next Source for Competitive Advantage", Journal of the Academy of Marketing Science. 1997: 25(2): 139.

[8] Hu Ruijing, "Literature review on Customer Perceived Value Theory", Modern commercial Industry. 2011: 23(07): 127-128.

[9] Sheth J N., Newman B I., Gross B L., "Why We Buy What We Buy: A Theory of Consumption Values", Journal of Business Research. 1991: 22(2): 159-170.

[10] Sweeney J C., Soutar G N., "Consumer perceived value: The development of a multiple item scale", Journal of Retailing. 2001: 77(2): 203-220.

[11] Cardozo R N., "An experimental study of customer effort, expectation, and satisfaction", Journal of Marketing Research. 1965: 2(3): 244-249.

[12] Oliver R L., "A Cognitive Model of the Antecedents and Consequences of Satisfaction Decisions", Journal of Marketing Research. 1980: 17(4):460-469.

[13] Bhattacherjee A., "Understanding Information Systems
Continuance: An Expectation-Confirmation Model", MIS Quarterly. 2001: 25(3): 351-370.

[14] Meng Shuang, "Use and Satisfaction - Barrage Video Audience Psychological Analysis", Journal of Propagation Force Research. 2018: 2 (12): 237.

[15] Yin Rong, Zhang Feifei, "The Mechanism of Group Identity in Cluster Behavior", Progress in Psychological Science. 2015: 23(09): 1637-1646.

[16] Chen Songsong, "Language Features and Expressive Meanings of Barrage Video", News World. 2015(07): 105-106.

[17] Chiu C M, Hsu M H, Wang E T G., "Understanding Knowledge Sharing in Virtual Communities: An Integration of Social Capital and Social Cognitive Theories", Decision Support Systems. 2007: 42(3): 1872-1888.

[18] Jin Liyin, "Influence of Value Dimension of Virtual Brand Community on Members' Sense of Community, Loyalty and Behavioral Tendency", Management Science. 2007(02): 36-45.

[19] Li Xianguo, Chen Ningjie, Zhang Xinsheng, "Influence Mechanism of Virtual Brand Community Perceived Value on Purchase Intention of New Products -- A Double-Intermediary Perspective Based on Group Identity And Brand Identity", China Circulation Economy. 2017: 31(02): 93-100.

[20] $\mathrm{Li} \mathrm{Wu,} \mathrm{"Research} \mathrm{on} \mathrm{the} \mathrm{Influence} \mathrm{of} \mathrm{Perceived} \mathrm{Value}$ on User Satisfaction and Loyalty of E-Book Readers", Journal of China Library. 2017: 43(06): 35-49.

[21] Zhong Qiuyan, Wang Yanjie, Qiu Jiangnan, “Empirical Study on Continuous Participation Behavior of Crowdsourcing Community Users", Journal of Dalian University of Technology (Social Science Edition). 2011: 32(01): 1-6.

[22] Baron, R. M., Kenny, D. A., “The Moderator-Mediator Variable Distinction in Social Psychological Research: Conceptual, Strategic and Statistical Considerations", Journal of Personality and Social Psychology. 1986: 51(6): 1173-1182. 